\title{
Clinical Significance of Microalbuminuria in High-Risk Patients With Coronary Artery Disease
}

\author{
Sunao Kojima, MD; Hisao Ogawa, MD
}

$\mathbf{T}$ here is strong evidence that individuals with chronic kidney disease (CKD) are more likely to die of cardiovascular disease than develop renal failure. ${ }^{1}$ Many of the traditional and nontraditional cardiovascular risk factors are associated with CKD. ${ }^{2}$ Related conditions such as diabetes, obesity and hypertension, as well as the presence of renal dysfunction per se, lead to the activation of the renin-angiotensin system, oxidative stress, elevated asymmetric dimethyl arginine, low-grade inflammation with hypercytokinemia and dyslipidemia and may play a role in the association of renal failure and cardiovascular disease. ${ }^{3}$ The coronary plaques in CKD patients have markedly higher lipid volume and lower fibrous volume, suggesting increased risk of cardiovascular events in such patients. ${ }^{4}$ However, there is growing evidence that relatively minor renal abnormalities, or microalbuminuria even within the normal range, may be associated with increased risk of cardiovascular events. ${ }^{2}$ Microalbuminuria is the strongest predictor of adverse cardiovascular outcome and the impact of microalbuminuria on the primary composite outcome is significant especially in patients with diabetes mellitus (DM). ${ }^{5}$ Although the mechanism of urinary excretion of albumin in association with the risk of cardiovascular events has not been fully elucidated, one of the main pathophysiological mechanisms is the development of endothelial dysfunction, leading to widespread vascular damage., ${ }^{2,6}$

\section{Article p 2893}

Patients with acute coronary syndrome (ACS) are reported to have greater amounts of necrotic core in the plaque found in their coronary arteries. ${ }^{7}$ Hypoadiponectinemia, which is frequently observed in patients with DM and metabolic syndrome, correlates with necrotic core lesions. ${ }^{8}$ In this issue of the Journal, Hong et $\mathrm{al}^{9}$ report that the necrotic core component, representing coronary plaque vulnerability, was significantly greater in patients with microalbuminuria than in those with normoalbuminuria. They also indicated that these findings were clearly evident in ACS and DM patients, and that microalbuminuria was an independent predictor of thin-cap fibroatheroma [defined as a necrotic core $\geq 10 \%$ of the plaque area in at least 3 consecutive frames without overlying fibrous tissue in the presence of $\geq 40 \%$ plaque burden on virtual histology-intravascular ultrasonography]. These findings may be helpful in stratifying patients according to coronary plaque vulnerability, especially those with ACS and DM. Aggressive medical treat- ment to stabilize coronary atherosclerotic plaques is needed for vulnerable patients to reduce the incidence of future cardiovascular events. The use of pharmacological agents to reduce plaque vulnerability has been explored and statins are representative of circulatory drugs that can reduce the occurrence of acute events in ACS patients. ${ }^{10}$ Intervention with statins in ACS patients enables significant reduction of coronary arterial plaque volume, mainly by decreasing the lipid component. ${ }^{11}$ In a multicenter study of an aggressive lipid-lowering strategy using HMG-CoA reductase inhibitors (the MUSASHI study), our group also reported that statin treatment provided incremental clinical benefit in normocholesterolemic DM patients with coronary artery disease. ${ }^{12}$ Among the 1,016 patients randomly assigned to statin therapy, a total of 301 (155 with statin therapy, 146 without statin therapy) were recognized as having type 2 DM. The non-DM group consisted of 715 patients (348 with statin therapy, 367 without statin therapy) (Table). Aggressive treatment with a statin seems to reduce major adverse cardiac events compared with mild statin therapy (MUSASHI-DM study) (Figure). ${ }^{13}$ On the other hand, intensive statin therapy in DM patients with ACS resulted in regression of plaque volume and a lower target level of low-density lipoprotein cholesterol

\begin{tabular}{|c|c|c|c|}
\hline & \multicolumn{3}{|c|}{ Statin treatment } \\
\hline & No & Mild* & Strong ${ }^{*}$ \\
\hline \multicolumn{4}{|l|}{ DM group } \\
\hline$n=301$ & 146 & 106 & 49 \\
\hline Baseline (mg/dl) & $130 \pm 20$ & $132 \pm 22$ & $135 \pm 22$ \\
\hline 6-month (mg/dl) & $125 \pm 27$ & $103 \pm 25$ & $84 \pm 29$ \\
\hline 1-year (mg/dl) & $124 \pm 30$ & $106 \pm 24$ & $90 \pm 28$ \\
\hline 2-year (mg/dl) & $121 \pm 36$ & $100 \pm 25$ & $87 \pm 29$ \\
\hline \multicolumn{4}{|l|}{ Non-DM group } \\
\hline$n=715$ & 367 & 239 & 109 \\
\hline Baseline (mg/dl) & $131 \pm 20$ & $132 \pm 20$ & $134 \pm 25$ \\
\hline 6-month (mg/dl) & $126 \pm 29$ & $103 \pm 23$ & $92 \pm 34$ \\
\hline 1-year (mg/dl) & $123 \pm 29$ & $102 \pm 25$ & $85 \pm 28$ \\
\hline 2-year (mg/dl) & $120 \pm 25$ & $100 \pm 25$ & $84 \pm 27$ \\
\hline
\end{tabular}

Data are mean \pm SD

${ }^{*} \mathrm{P}<0.0001$ vs. non-statin treatment by repeated measures ANOVA in DM group and non-DM group, respectively.

LDL-C, low-density lipoprotein cholesterol; DM, diabetes mellitus. (Modified from Kojima S et al. ${ }^{12}$ )

The opinions expressed in this article are not necessarily those of the editors or of the Japanese Circulation Society.

Received October 11, 2011; accepted October 12, 2011; released online November 1, 2011

Department of Cardiovascular Medicine, Graduate School of Medical Sciences, Kumamoto University, Kumamoto, Japan

Mailing address: Sunao Kojima, MD, Department of Cardiovascular Medicine, Graduate School of Medical Sciences, Kumamoto University,

1-1-1 Honjo, Kumamoto 860-8556, Japan. E-mail: kojimas@ kumamoto-u.ac.jp

ISSN-1346-9843 doi:10.1253/circj.CJ-11-1167

All rights are reserved to the Japanese Circulation Society. For permissions, please e-mail: cj@j-circ.or.jp 

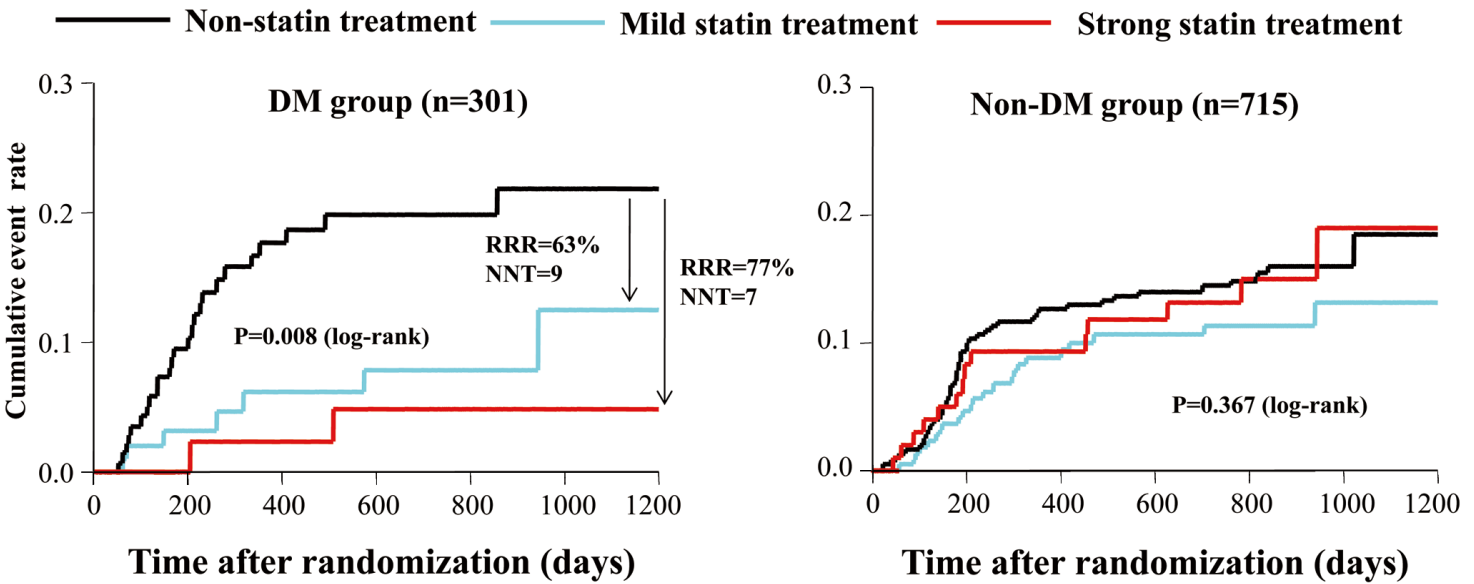

Figure. Cumulative cardiovascular event rates in diabetic and non-diabetic subjects according to statin therapy. The primary endpoint was a composite of cardiovascular death, non-fatal acute myocardial infarction, unstable angina, congestive heart failure and stroke. DM, diabetes mellitus; NNT, number needed to treat; RRR, relative risk reduction. (Modified from Kojima S et al. ${ }^{12}$ )

(LDL-C). ${ }^{14}$ Therefore, DM carries a distinctive burden of coronary risk and sufficient reduction of the LDL-C level is recommended even if DM is the sole risk factor for coronary artery disease. The clinical significance of microalbuminuria reported by Hong et $\mathrm{al}^{9}$ should allow stratification of ACS and DM patients and the clinical management of such patients may be strengthened with the addition of statins.

How do statins influence microalbuminuria through their beneficial effect on coronary plaque stabilization? Bianchi et al reported that the combination of statins and angiotensinconverting enzyme inhibitors or angiotensin II receptor blockers seems to reduce proteinuria and the rate of progression of kidney disease in patients with CKD and significant proteinuria. ${ }^{15}$ The urinary protein-lowering activity of statins may be related to plaque stabilization. At this stage, large randomized controlled studies are necessary to confirm these preliminary findings.

\section{References}

1. Shrnak MJ, Levey AS, Schoolwerth AC, Colleton B, Hamm LL, McCullough PA, et al. Kidney disease as a risk factor for development of cardiovascular disease: A statement from the American Heart Association Councils on Kidney in Cardiovascular Disease, High Blood Pressure Research, Clinical Cardiology, and Epidemiology and Prevention. Hypertension 2003; 42: 1050-1065.

2. Sciffrin EL, Lipman ML, Mann JFE. Chronic kidney disease: Effects on the cardiovascular system. Circulation 2007; 116: 85-97.

3. Amann K, Wanner C, Ritz E. Cross-talk between the kidney and the cardiovascular system. J Am Soc Nephrol 2006; 17: 2112-2119.

4. Miyagi M, Ishii H, Murakami R, Isobe S, Hayashi M, Amano T, et al. Impact of renal function on coronary plaque composition. Nephrol Dial Transplant 2010; 25: 175-181.

5. Mattock MB, Barnes DJ, Viberti G, Keen H, Burt D, Hughes JM, et al. Microalbuminuria and coronary heart disease in NIDDM: An incidence study. Diabetes 1998; 47: 1786-1792.

6. Deckert T, Feldt-Rasmussen B, Borch-Johnsen K, Kofoed-Enevoldsen
A. Albuminuria reflects widespread vascular damage: The steno hypothesis. Diabetologia 1989; 32: 219-226.

7. Hong MK, Mintz GS, Lee CW, Suh J, Kim JH, Park DW, et al. Comparison of Virtual Histology to intravascular ultrasound of culprit coronary lesions in acute coronary syndrome and target coronary lesions in stable angina pectoris. Am J Cardiol 2007; 100: 953-959.

8. Kojima S, Kojima S, Maruyoshi H, Nagayoshi Y, Kaikita K, Sumida $\mathrm{H}$, et al. Hypercholesterolemia and hypoadiponectinemia are associated with necrotic core-rich coronary plaque. Int J Cardiol 2011; 147: $371-376$.

9. Hong YJ, Jeong MH, Choi YH, Song JA, Ahmed K, Kim DH, et al. Relation between microalbuminuria and vulnerable plaque components in patients with acute coronary syndrome and with diabetes mellitus: Virtual histology-intravascular ultrasound. Circ J 2011; 75: $2893-2901$

10. Monroe VS, Kerensky RA, Rivera E, Smith KM, Pepine CJ. Pharmacologic plaque passivation for the reduction of recurrent cardiac events in acute coronary syndromes. $J$ Am Coll Cardiol 2003; 41: $23 \mathrm{~S}-30 \mathrm{~S}$.

11. Otagiri K, Tsutui H, Kumazaki S, Miyashita Y, Aizawa K, Koshikawa $\mathrm{M}$, et al. Early intervention with rosuvastatin decreases the lipid components of the plaque in acute coronary syndrome: Analysis using integrated backscatter IVUS (ELAN study). Circ J 2011; 75: 633-641.

12. Kojima S, Sakamoto T, Ogawa H, Kitagawa A, Matsui K, Shimomura $\mathrm{H}$, et al; MUSASHI investigators. Standard-dose statin therapy provides incremental clinical benefit in normocholesterolemic diabetic patients. Circ J 2010; 74: 779-785.

13. Kojima S, Sakamoto T, Kitagawa A, Matsui K, Ogawa H; MUSASHI investigators. Strong statin treatment provides incremental clinical benefit in normocholesterolemic diabetic patients with coronary heart disease (abstracts from scientific sessions 2011). Circulation 2011 (in press).

14. Arai H, Hiro T, Kimura T, Morimoto T, Miyauchi K, Nakagawa Y, et al; Japan-ACS investigators. More intensive lipid lowering is associated with regression of coronary atherosclerosis in diabetic patients with acute coronary syndrome: Sub-analysis of Japan-ACS study. $J$ Atheroscler Thromb 2010; 17: 1096-1107.

15. Bianchi S, Bigazzi R, Caiazza A, Campese VM. A controlled, prospective study of the effects of atorvastatin on proteinuria and progression of kidney disease. Am J Kidney Dis 2003; 41: 565-570. 